\title{
As Conchas de Ruskin
}

\section{John Ruskin's Shells}

\section{Christopher Donaldson*}

*É professor-pesquisador da Universidade Lancaster desde 2012, envolvido na pesquisa do ERC-funded Spatial Humanities project. Trabalhou na University of Birmingham entre 2014 e 2016. Formou-se nos estados unidos, recebendo seu BA na Penn State University em 2004 e seu PhD na Stanford University em 2012. Sua pesquisa concentra-se nos séculos 18 e 19 no campo da história e cultura. Interessado na mudança das percepções da paisagem e do ambiente durante este período através da produção de guias turísticos, livros topográficos, de artes e literatura. Desenvolve e é líder da pesquisa no The Ruskin - Library, Museum and Research Centre, além de editor da revista The Ruskin Review e co-editor da Digital Forum para o Journal of Victorian Culture, c.e.donaldson@lancaster.ac.uk.

\section{Palavras-chave:}

\section{Ciência.}

História natural.

Coleções.

Estética.

\section{Keywords:}

Science.

Natural history.

Collections.

Aesthetics.

\section{Resumo}

John Ruskin (1819-1900) formou uma coleção impressionante de conchas ao longo de sua vida. Durante seus últimos anos de vida, ele expôs alguns dos frutos de seu trabalho em Brantwood, sua residência com vista para o lago Coniston Water, ao noroeste da Inglaterra. Ruskin estimava suas conchas por sua beleza. Ele as colocou em um armário de vidro junto com espécimes geológicos, artefatos históricos e obras de arte. Mas o interesse de Ruskin em sua coleção de conchas não era superficial. No presente artigo, pondero a respeito do real significado encontrado por Ruskin em suas conchas, tanto marinhas como terrestres, e reflito sobre como seus estudos sobre as conchas mostram princípios de seus escritos sobre arte e arquitetura, bem como sua atitude quanto às ciências naturais. A fim de definir uma abordagem para essas questões, começo este artigo considerando as opiniões de outros autores que escreveram sobre a beleza e peculiaridade das conchas. Procuro então contrastar tais apreciações estéticas com as conchas. Procuro então contrastar tais apreciações estét
contemplações mais eticamente esclarecidas de Ruskin.

\section{Abstract}

John Ruskin (1819-1900) assembled an impressive collection of shells over the course of his life. During his final years he displayed some of the fruits of his labours at Brantwood, his home overlooking Coniston Water in the northwest of England. Ruskin valued these shells for their beauty. He put them in a glass cabinet alongside geological specimens, historical artefacts and works of art. But Ruskin's this essay, ponder the deeper meaning Ruskin discovered in the shells he collected, both marine and terrestrial, and I suggest how his shell studies reflect principles developed in his writings on art and architecture, as well as his attitude towards the natural sciences. In order to stake an approach to these issues, I begin this essay by considering the remarks of other writers who have commented on the beauty and curioity of shells. I then proceed to contrast these aesthetic appreciations with Ruskin's more ethically informed contemplations. 


\section{As Conchas de Ruskin}

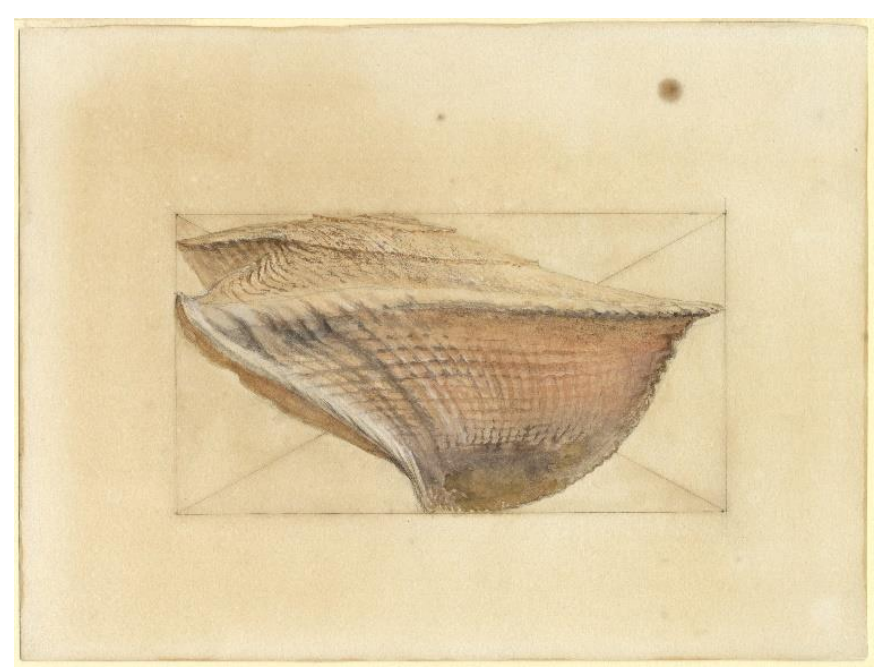

Figura 1. John Ruskin, "Estudo de conchas" (espiral de helix gualterianas), n.d.; lápis, aquarela e guache, 145 × $24 \mathrm{~cm}$. Inventário n. 1996P0993 @ The Ruskin - Biblioteca, Museu e Centro de Pesquisa, Universidade de Lancaster

\section{I.}

O que as conchas podem nos mostrar? - potencialmente algo bom. Suas formas e contornos fazem delas objeto de admiração, mas elas também são enigmáticas. Elas nos revelam mundos uma vez inerentes e misteriosos, e é justamente nisso que mora parte de seus atrativos. Como Abbé de Vallemont observou, as conchas são mais do que apenas "os deleites de grandes homens"; também são "sublimes objetos de contemplação para a mente." $\left(1705\right.$, p.648) ${ }^{1}$

Em A Poética do Espaço, Gaston Bachelard dedica um capítulo à enumeração de tais contemplações, incluindo as de Vallemont. Seu objetivo é desenvolver um entendimento da concha como um tipo espacial específico: definido pela interação de ideias opostas tais como grande e pequeno, notado e despercebido, mole e duro. (1961, p.111) A abordagem de Bachelard é mais poética do que sistemática,

${ }^{1}$ «Qu'il nous soit permis de jetter un moment les yeux fur cette ravissante variété de Coquillages qui sont les délices des grands hommes [. . . ] de sublimes sujets de contemplation pour l'esprit. " A menos que estejam creditadas de outro modo, todas as traduções são minhas. mas ao ponderar essas antíteses ele destaca a imagem persistente da concha como um espaço reservado e, ao mesmo tempo, um local secretamente moldado pelo corpo de seu habitante solitário.

Os pensamentos de Bachelard em torno deste último aspecto basearam as reflexões de Paul Valéry em L'Homme et la coquille. As conchas, conforme Valéry pontua em seu trabalho, não são secretas apenas por servirem como esconderijos, mas também por terem sido reservadas pelas criaturas que elas esconderam em primeiro lugar.

Simplificando, conchas são exoesqueletos compostos de cálcio cristalizado filtrado (ou "exsudado", de acordo com Valéry) através dos tecidos de moluscos e outros invertebrados.' (1937, p.68) Os resultados desse longo e contínuo processo de formação são perceptíveis. Mas o processo em si é imperceptível a um olho não treinado.

Tal fato ajuda a considerar a maravilha que as conchas inspiram em nós, que desenvolvemos nosso esqueleto dentro de nossos corpos. Nas palavras de Valéry, "por mais que tenhamos sido formados por um crescimento imperceptível, não sabemos criar nada dessa maneira." (1937, p.15; trans. MANHEIM 1977, p.113)

As implicações dessa asserção são bem simples. Se tivéssemos que criar uma concha, não o faríamos como os moluscos fazem. Para começar, provavelmente esculpiríamos nossa concha, começando de fora para dentro. Mas essa não é a única e nem mais importante diferença. Enquanto os moluscos constroem suas conchas involuntariamente, com um propósito perfeito, nós as construiríamos intencional e deliberadamente, e o trabalho que produziríamos seria no máximo indiretamente relacionado a (o que Valéry chama) "nossa atividade orgânica fundamental". (1937, p.65; trans. MANHEIM 1977, p.122)

${ }^{2}$ «Une coquille émane d'un mollusque. Emaner me semble le seul terme assez près du vrai, puisqu'il signifie properment: laisser suinter. " (O que está em itálico é de Valéry.)

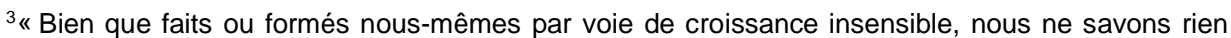
créer par cette voie. "

${ }^{4}$ " [C]'est pourquoi nos desseins réfléchis et nos constructions ou fabrications voulues semblent très étrangers à notre activité organique profonde. " (O que está em itálico é de Valéry.) 
II.

Penso que tudo isso pode ser dito a respeito da estética das conchas. Mas existe também uma ética de conchas que tanto Valéry quanto Bachelard abordam, mas que nenhum dos dois explica. A asserção de Valéry sobre nossa incapacidade de construir como os moluscos é indicativa. Ele não pondera as implicações éticas dessa afirmação, mas não é necessário muito para perceber como seus pensamentos andam de acordo com a filosofia de naturalistas pré-modernos como Vallemont, que colocava as conchas entre as maravilhas que "humilham e mortificam as mentes orgulhosas." $(1705$, p.634)

Tais observações são dignas de registro, mas a ética que tenho em mente se relaciona com outra propriedade maravilhosa das conchas: o modo como conseguem passar de uma vida a outra.

Conchas podem parecer bem sólidas, mas elas também se despedaçam, quebram e dissolvem, e conforme entram em decomposição elas se tornam os minerais ingeridos e expelidos por outros organismos. Nesse sentido, as conchas são parte dos contínuos ciclos biogeoquímicos que deram forma à ecologia do nosso planeta.

A artista britânica Janet Manifold explorou recentemente esse aspecto das conchas em sua escultura, Time Unfolding. Na descrição da obra, Manifold reflete sobre a formação do alabastro que compõe sua escultura.

Ela explica que essa substância fora "parte de um oceano vivo 23 anos atrás." Ela foi formada a partir dos depósitos de cálcio deixados pela "água do mar evaporada", a qual "fluiu através" das criaturas "as escondendo em suas conchas" por um longo tempo. "Então, ao abrir esta pedra para criar uma escultura, estamos voltando no tempo para a origem do material em si, bem como para a vida que ele um dia gerou." (MANIFOLD 2019)

Visto desta maneira, Time Unfolding clareia as interligações de todas as coisas, passado e presente, animado e inanimado. Como escultura, é uma sofisticada

${ }^{5}$ "Dans la Nature on est rarement en pays de connaissance. Il y a à chaque pas de quoi humilier, et mortifier les Esprits superbes. " reflexão tanto sobre a natureza do material do que é feita, como, por analogia, sobre a natureza como um todo.

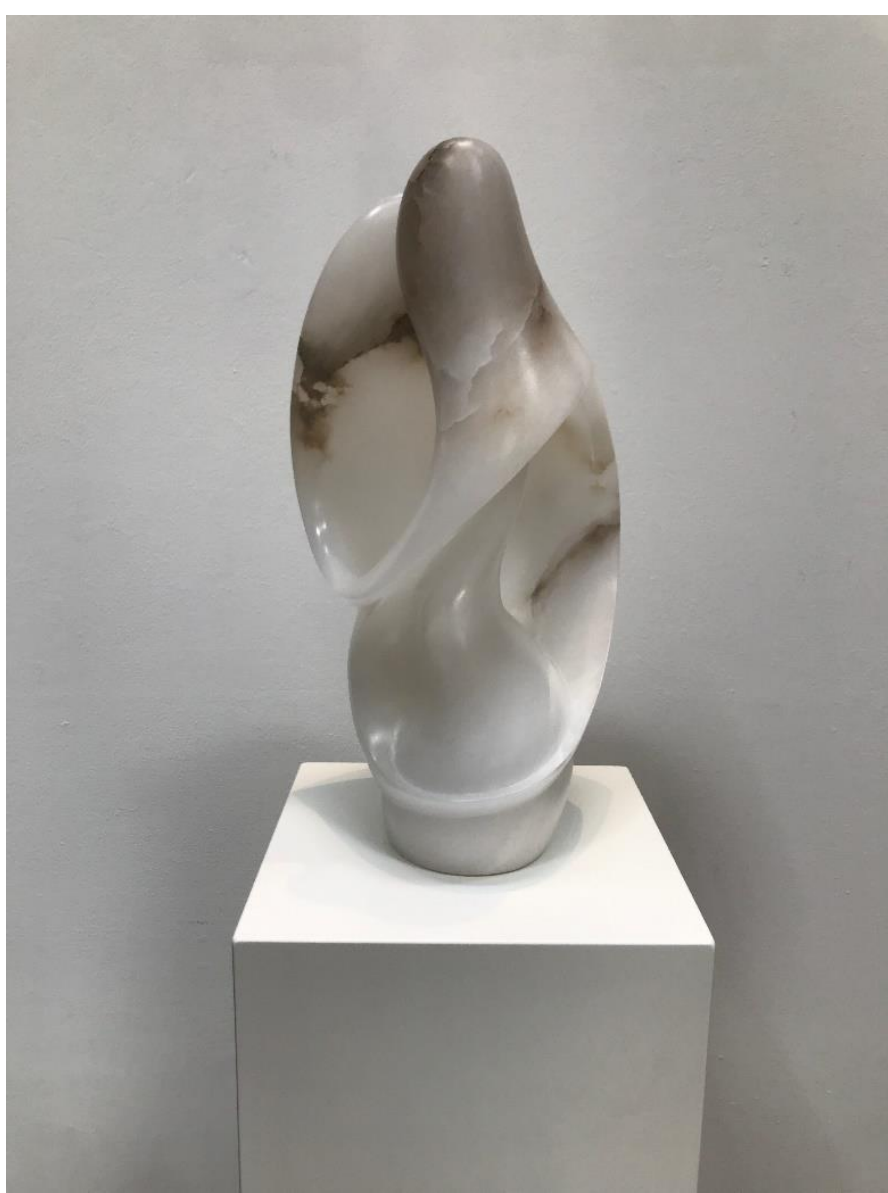

Figura 2. Janet Manifold, Time Unfolding, 2019; alabastro esculpido, $25 \times 25 \times 40 \mathrm{~cm}$. @ Janet Manifold. Imagem cedida pela artista.

Com certeza, pode-se encontrar mais exemplos comuns de como as conchas passaram de um estado para outro e de uma vida para a outra. Os fertilizantes, por exemplo. Há tempos os humanos fazem cal das conchas para enriquecer o adubo. Essa prática foi registrada por Pliny the Elder e em outras fontes romanas, 
${ }^{6}$ bem como em manuais de agricultura mais recentes. Assim, o The American Muck Book, um clássico de meados do século XIX sobre o assunto, diz que "o fazendeiro encontrará um valioso adubo nas conchas de ostras, mariscos e outros moluscos de concha, reduzindo-as a pó ao queimá-las em fornos, ou moê-las em moedores." (BROWNE 1852, p.313)

E o cal é bom para muito mais do que apenas adubo. Também é um componente essencial em concreto e argamassa, bem como na fabricação de ferro, aço e vidro laminado. Portanto, em resumo, as conchas não só ajudam em nossa alimentação como também formam nosso meio ambiente. Em ambos os casos, o uso de conchas decompostas fundamentalmente moldou o mundo moderno.

Mas a decomposição é apenas uma das maneiras nas quais conchas são recicladas. Elas podem se tornar uma segunda casa, afinal. Alguém pode pensar nas conchas que caranguejos-eremitas se apoderam e em como conchas fossilizadas podem se tornar um lar para futuras formas de vida. Em cada caso o estudo das conchas revela a importância da cooperação e interdependência como forças ativas na natureza.

Isso não é algo discutido por Valéry e Bachelard, mas é certamente um aspecto dos estudos de conchas que interessava John Ruskin. Seu relato sobre colecionar conchas durante suas férias de verão em Boulogne, em 1861, o qual abordarei em breve, oferece um bom exemplo desse aspecto.

III.

Ruskin começou a colecionar conchas ainda criança, e ao fim de sua vida, tinha formado uma coleção impressionante. Durante seus últimos anos, ele dispôs alguns dos frutos de seus trabalhos na sala de estar em Brantwood, sua casa com vista para o lago Coniston Water, no distrito de English Lake.

Ruskin estimava suas conchas por sua beleza. Ele as colocou em um armário de vidro junto com espécimes geológicos, artefatos históricos e obras de arte. Um visitante de Brantwood em 1884 descreveu essa coleção em detalhes. Ele se recorda de ter visto "variedades infinitas de conchas, muito raras e belas, e alguns minerais de diferentes formações", com "exemplares extraordinários de cloisonné esmaltado", bem como "exóticos exemplares dos desenhos a lápis de Prout, Burne-Jones (Fair Rosamund), e dos próprios estudos de Ruskin [. . .] sobre St. Mark". (SPEILMAN 1900, p.133)

Uma foto (Fig. 3) tirada ao final do século XX é um registro visual desta cena.

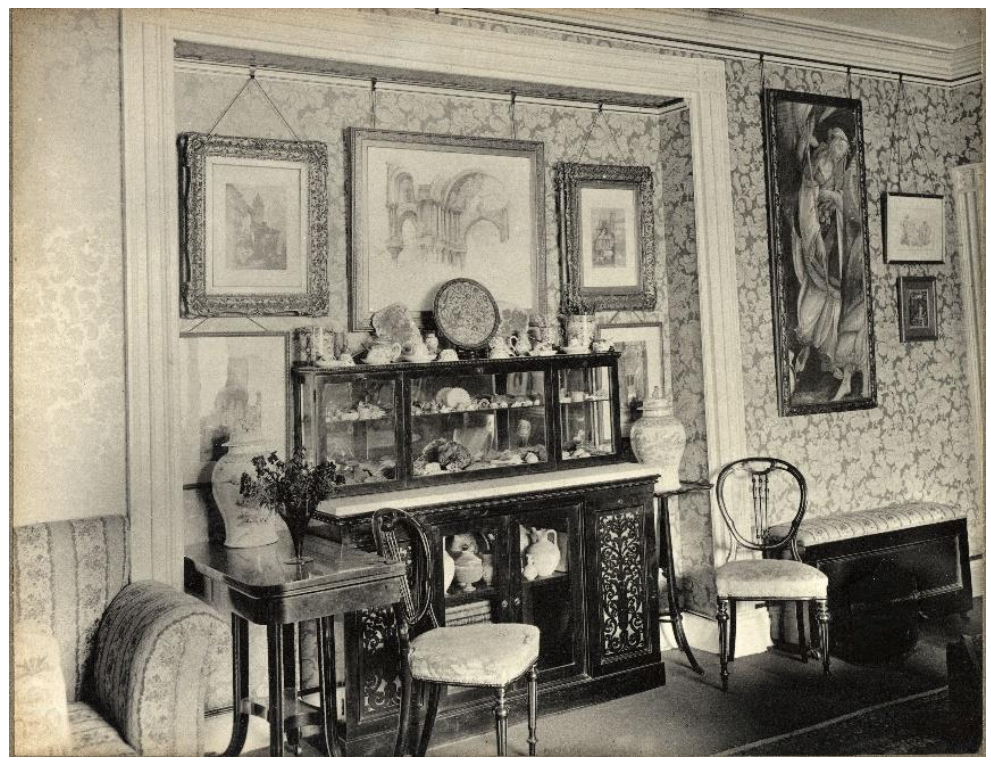

Figura 3. Walmsley Bros., "Sala de estar - Armário de Conchas, Brantwood" (c.1900); foto ๑ The Ruskin - Biblioteca, Museu e Centro de Pesquisa, Universidade de Lancaster

Esse assemelha-se menos com um depósito de um cientista do que um Wunderkammer de um conhecedor da área. Mas seria errado pensar que o interesse de Ruskin nessas conchas era meramente superficial. Assim como no caso dos outros objetos que ele dispunha em sua sala de estar, o que o atraía era a sensação de que esses refletiam leis morais.

As observações de Ruskin a respeito dos fósseis de conchas que coletou ao vasculhar a praia em Boulogne, em junho de 1861, são indicativas. Ele descreveu tal descoberta em uma carta enviada a seu pai no dia seguinte:

${ }^{6}$ PLINY 1962, p.77-78. 
Ontem estive na praia por bastante tempo, - e carreguei um pesado bloco de pedra por oito quilômetros à casa-um conjunto de fósseis de conchas de carbonato de cálcio, com todas as suas dobras e delicados espirais preservadosconchas que abrigaram peixes bem antes da existência de Mont Blanc, quando o cume da Aiguille de Varens era apenas lama no fundo do mar profundo; ainda assim, a marca de ondulação da pedra areia que as engloba é tão fresca como aquela há tempos desgastada, graças a maré agora em retirada. E os modernos búzios e mexilhões se escondem nas cavidades de conchas mortas há trinta mil anos. (RUSKIN 1905a, p.xxxvii)

Essa passagem é digna de registro por várias razões, em particular por prover uma noção até que ponto Ruskin estava disposto a ir para coletar espécimes interessantes. Arrastar "por oito quilômetros até a casa" aquele "bloco de pedra" deve ser sido um grande fardo. Há também o modo como as reflexões de Ruskin apresentam consciência sobre processos geológicos. Sua referência casual a orogênese da montanha Aiguille de Varens é particularmente notável.

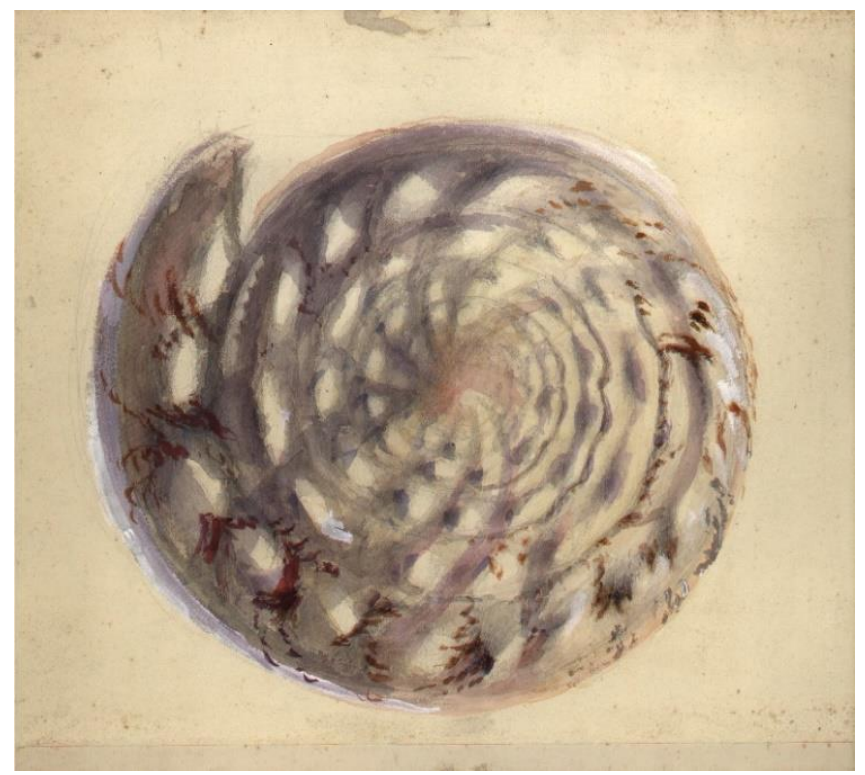

Figura 4. John Ruskin, "Concha: Um espiral" (concha cone-de-mármore), n.d.; guache e branco, 34.3 x 47.6 cm. Inventário n. 1996P2047 @ The Ruskin - Biblioteca, Museu e Centro de Pesquisa
Mas o que é realmente notável nessa passagem é como os comentários de Ruskin escancaram e abrem caminho para a ideia de Tempo Profundo. Por um lado, os "modernos búzios e mexilhões" e os "fósseis de conchas" são de eras distantes. Por outro lado, eles coexistem: aqueles encontram um local para viver nos restos destes. Assim como "a marca de ondulação" desgastada na "pedra areia" e a linha da "maré agora em retirada", a coexistência desses organismos antigos e modernos aumenta nossa consciência sobre a diferença temporal entre eles, ao mesmo tempo em que resolve essa diferença em uma imagem de continuidade.

Portanto, para Ruskin, a beleza daquele "conjunto de fósseis de conchas" pareceria ter se apoiado menos em sua origem vertiginosa do que no modo como havia criado as condições para um mundo futuro. As "cavidades" feitas por aqueles "peixes", "mortos há três mil anos", eram valiosas por terem sido esconderijo e preservação para vidas futuras.

\section{IV.}

Como já mencionei, o interesse de Ruskin por conchas era guiado por sua crença de que a natureza refletia leis morais. Ter isso em mente ajudará a elucidar seus comentários sobre os fósseis de conchas achados por ele em Boulogne, em 1861.

Aquelas conchas eram uma manifestação notável de um princípio que ele havia elaborado apenas um ano antes. Me refiro a "Lei da Ajuda".

Ruskin havia introduzido esse princípio no quinto volume de Modern Painters como uma das "leis elementares de disposição" contidas na composição de verdadeiras obras de arte. (RUSKIN 1905b, p.204) Tal "composição", ele explica, "pode ser definida como a ajuda de todas as coisas em uma situação por todo o resto". E tal "ajuda", ele continua, reflete a cooperação encontrada na vida orgânica saudável:

No caso das substâncias chamadas de "inanimadas", como nuvens e pedras, seus átomos podem se unir uns aos outros ou estar em harmonia, mas eles não se ajudam. A remoção de uma das partes não altera o todo.

Mas no caso de uma planta, retirar qualquer parte prejudica o restante. Danifique ou remova qualquer porção de seiva, súber, ou medula, e todo o resto estará danificado. Se qualquer parte atingir um estado em que não mais auxilia o todo, e portanto se torna "inútil", a chamaremos de "morta".

A esse poder que faz diversas partes de uma planta ajudar as demais, damos o 
nome de vida. E isso é muito mais evidente no caso dos animais. Nós podemos tirar um galho de uma árvore sem muitos danos; mas o mesmo não pode ser feito com um membro de um animal. Portanto, a intensidade da vida também é intensidade de utilidade — unidade de dependência de cada parte em relação ao todo. (RUSKIN 1905', p.205)

O impulso dessas distinções é razoavelmente óbvio. Elas esclarecem que, mesmo que o interesse de Ruskin na "Lei da Ajuda" em Modern Painters fosse principalmente ilustrativo, em sua mente, o princípio da "ajuda" era necessariamente conectado com um entendimento ético de ecologia: do modo como todas as formas de vida dependem umas das outras.

Refletir sobre essa passagem se relaciona com a explicação da razão pela qua aqueles fósseis de conchas mexeram tanto com a imaginação de Ruskin. Eles eram, afinal, a personificação do modo como os mortos ajudaram a moldar o mundo dos vivos.

Mas isso não é tudo. Ao exemplificar a dependência dos vivos em relação aos mortos, aquelas conchas remetem a outro aspecto significativo da ideia de Ruskin sobre cooperação: sua caracterização do poder da arquitetura de formar uma ponte entre passado e presente.

Ruskin havia desenvolvido essa ideia onze anos antes em The Seven Lamps of Architecture, no qual refletiu sobre como construções históricas são capazes de conectar sucessivas eras. A passagem é uma das partes mais citadas dos trabaIhos de Ruskin, mas vale a pena relembra-la aqui:

Pois, de fato, a maior glória de uma construção não reside em suas pedras, nem em seu ouro. Sua glória está em sua Era, e no profundo senso de possuir uma voz [. . . ] que sentimos nas paredes que há tempos foram lavadas pelas ondas passageiras da humanidade. Isso está em seu contínuo testemunho contra os homens, em seu silencioso contraste com o caráter transicional de todas as coisas, e na força que, através dos lapsos das estações e do tempo [. . .] mantém sua elegância esculpida temporariamente insuperável, [e] conecta eras esquecidas e futuras [.] (RUSKIN 1903, p.233-34)

Inicialmente, a "elegância esculpida" de tais construções pode parecer bem diferente das cavidades deixadas pelas conchas cujos fósseis Ruskin encontrou em Boulogne. Mas elas são análogas. Ambas conectam "eras esquecidas e futuras." Ambas ilustram a importância da "ajuda" como princípio de sucessão. Ambas demonstram a contínua dependência do presente em relação ao passado e, de modo implícito, do amanhã em relação ao hoje.

V.

Relembrar essas passagens dos trabalhos de Ruskin ajuda a iluminar a dimensão moral de seu interesse naqueles fósseis de conchas, e isso revela muito sobre sua atitude a respeito das ciências naturais. Isso é, nos lembra de que, para Ruskin, a ciência tinha tanto a ver com o estudo da natureza quanto com devoção. ${ }^{7}$

Reconhecer esse aspecto do pensamento de Ruskin ajuda a explicar a razão pela qual ele era desdenhoso em relação a Conquiliologia, apesar de ser um colecionador de conchas. Em um artigo dedicado a esse assunto, Stanley Peter Dance supôs que Ruskin achava que conquiliologistas perdiam muito tempo em detalhes triviais.

Na carta 63 de Fors Clavigera, Ruskin nos deu uma bela demonstração desse fato ao revelar a dificuldade em usar o Manual de Conquiliologia (1859), de Jean Charles Chenu, para responder uma simples questão sobre caracóis.

"Considerando que minha concha seja uma Helix virgata," ele escreve:

Eu utilizo meu magnífico francês- (deixe-me ver se consigo escrever o título sem erros) -Manuel de Conchyliologie et de Paléontologie Conchyliologique, ou, em português, "Manual de Conquiliologia e Paleontologia da Conquiliologia". Octavo de 800 páginas impressas,-mais parecido com um fólio—com 4.000 (quase 5.000) sofisticadas gravuras de conchas; e entre elas procuro as criaturas nomeadas elegante e incorretamente pelos naturalistas modernos como Gastrópodes; e entre elas encontrei, com muito pesar, uma concha muito parecida com a minha, que dizem pertencer ao $16^{\circ}$ tipo na segunda tribo, da segunda família, da primeira subordem, da segunda ordem das Gastrópodes, e que recebe o nome de Adeorbis subcarinatus,-_Adeorbis pelo Sr. Wood, e subcarinatus pelo Sr. Montagu; mas não sou informado de onde posso encontrá-la, nem que tipo de criaturas vivem nela, nem qualquer outra informação a não ser o fato de ser "suficientemente depressiva" (assez déprimée), e "profundamente umbilicada" (assez profondement ombiliquée,-mas como posso dizer que uma concha é umbilicada a uma profundidade, na opinião do autor, satisfatória?), e que suas curvas (comuns na família) são "poucas" (peu nombreux). No final das con-

\footnotetext{
7Veja BIRCH 1981, O'GORMANN 1999 e HEWISON 2020.
} 
tas, estou propenso a acreditar que minha concha não está descrita aqui, e então coloco meu esplêndido livro de volta ao seu lugar. (RUSKIN 1907, p.552-53)

Aqui, Ruskin descreve como vasculhou o "octavo de dezesseis volumes" da tradução de Griffith da obra O Reino Animal, de Cuvier, para encontrar uma resposta. (1907, p.553) Contudo, mais uma vez, sua pesquisa é em vão.

Este tipo de bobice sobre o burburinho da ciência faz parte do engajamento de Ruskin com as ciências durante a metade final de sua carreira. Mas no que diz respeito ao estudo de conchas em particular, esses comentários ajudam a esclarecer a razão pela qual ele alertou Henrietta Carey de que a Conquiliologia "não acrescentava em nada como estudo". (qt. Dance 2004, p.43)

Ruskin pode ter tido cópias de Chenu e Cuvier em seu escritório, mas estava evidentemente mais interessado nas "elegantes gravuras" contidas nesses livros. Ele considerava suas descrições das classes, ordens, gêneros e espécies específicos como de interesse secundário, e desdenhava de suas discussões sobre anatomia.

Uma das cartas de Ruskin a Carey, de 11 de fevereiro de 1883, esclareceu esses fatos. Aqui, ele conta ter "cortado em pedacinhos" sua cópia de Cuvier:

A primeira coisa que encontrei para você foi a parte a parte principal dos desenhos anatômicos dos moluscos, estrelas-do-mar, medusas e corais, informados na última edição de Reino Animal, de Cuvier. Os camarões e caranguejos seguem [. . . ]. Picotei o livro inteiro para poder queimar seus nojentos desenhos anatômicos [. . . ]. Alguns dos [outros] desenhos anatômicos foram enquadrados para meus departamentos em Oxford, mas não faço ideia do local onde as outras conchas foram parar. Entretanto, esses desenhos anatômicos, guardados em diferentes embrulhos fortificados, podem ser usados para cópias de outros desenhos. Essas cópias, quando boas o suficiente, devem ser mantidas para usos futuros a beira do mar ou em museus. (qt. Dance 2004, p.43)

Alguns dias depois, Ruskin também enviou a Carey uma cópia do manual de Chenu, com uma carta a informando de que o livro, "apesar de extremamente seco nas palavras, tem desenhos anatômicos adoráveis'. (qt. Dance 2004, p.43)

Em sua discussão sobre essa correspondência, Dance supõe que o interesse de Ruskin em conchas era mais artístico do que científico. Ele escreve que Ruskin

${ }^{8}$ Carey (c.1844-1920) foi uma antiga Colaboradora do Guild of St George com quem Ruskin compartilhou uma porção considerável de sua coleção de conchas, bem como outros materiais, durante o inicio dos anos 1880. Veja Dance (2004) para ter acesso as suas correspondências. colecionava conchas para desenhá-las, e "ele as desenhava em partes porque gostava delas e em partes porque queria provar que era capaz de fazê-lo." (2004, p.37)

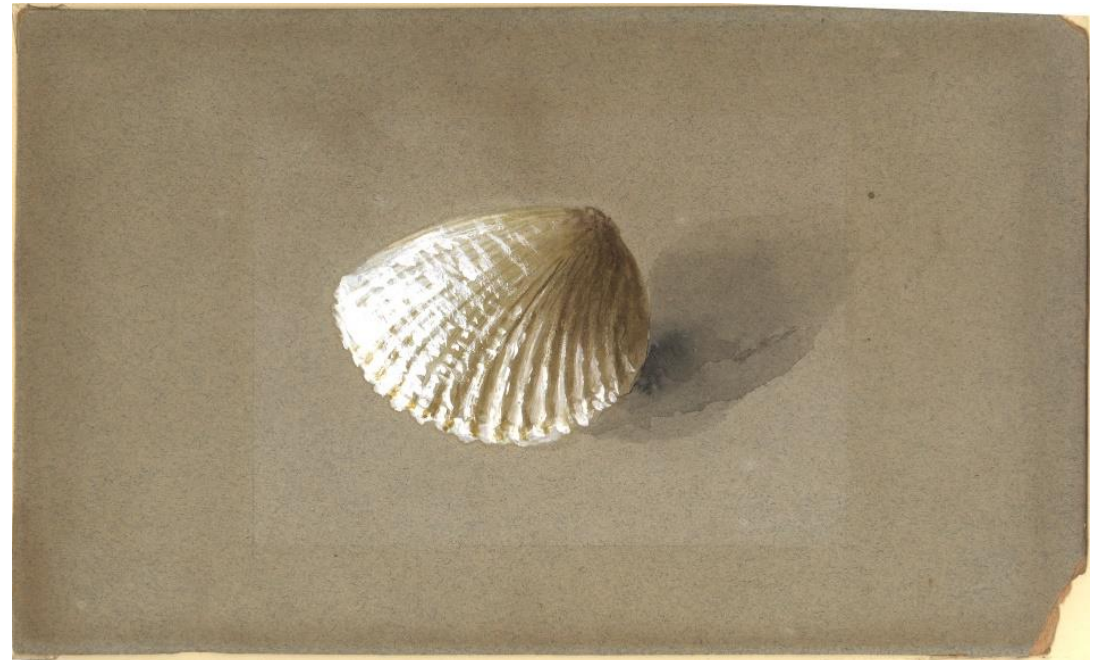

Figura 5. John Ruskin, 'Cerastoderma' (1876); lápis, aquarela e guache, $14.5 \times 24 \mathrm{~cm}$. Inventário n. 1996 P1510 @ The Ruskin - Biblioteca, Museu e Centro de Pesquisa

VI.

Há certo mérito nessas afirmações. Conforme Dance coloca, Ruskin regularmente exercitava sua visão e habilidades pintando conchas, e reafirmou diversas vezes o quão difícil era desenhá-las direito. Ele comentou sobre essa dificuldade em suas duas obras publicadas e em suas cartas pessoais.

Em The Laws of Fésole, ele descreveu a Cerastoderma como sendo "na realidade, imensamente difícil, e em sua condição final, impossível de ser imitada pela arte". (RUSKIN 1904, p.410) Do mesmo modo, em uma carta de agradecimento a Sydney Carlyle Cockerel por ter Ihe enviado uma caixa de conchas em 1886, Ruskin comentou que "existem poucas coisas pelas quais me interesso [. . .], ou me preocupo mais em tentar desenhar, em vão." (qt. MEYNELL 1940, p.20) 
Apesar dessa dificuldade, ou talvez por causa dela, Ruskin perseverou. Ao todo, ele é conhecido por ter completado em torno de 24 estudos de conchas, e usou muitos desses desenhos como modelos para seus alunos. Ele claramente considerava a habilidade de desenhar bem uma concha como marcador de virtuosidade.

Para provar isso, basta ler uma carta que Ruskin enviou ao seu pai em março de 1859. "Conchas", escreve Ruskin:

são [. . . ] fáceis até certo ponto [e] ficam lindas uma vez que você dá a elas um tratamento final. Mas pintá-las com realismo-e com seu exato brilho ou textura perolada, é tarefa apenas para os mais habilidosos - e acredito que seja mais um Tour-de-force do que um mero objeto de entretenimento em seu rodapé, no qual Ticiano introduz uma concha de caracol. No Sepultamento existem duastalvez para mostrar a umidade da pedra. (qt. BURD 1969, p.108)

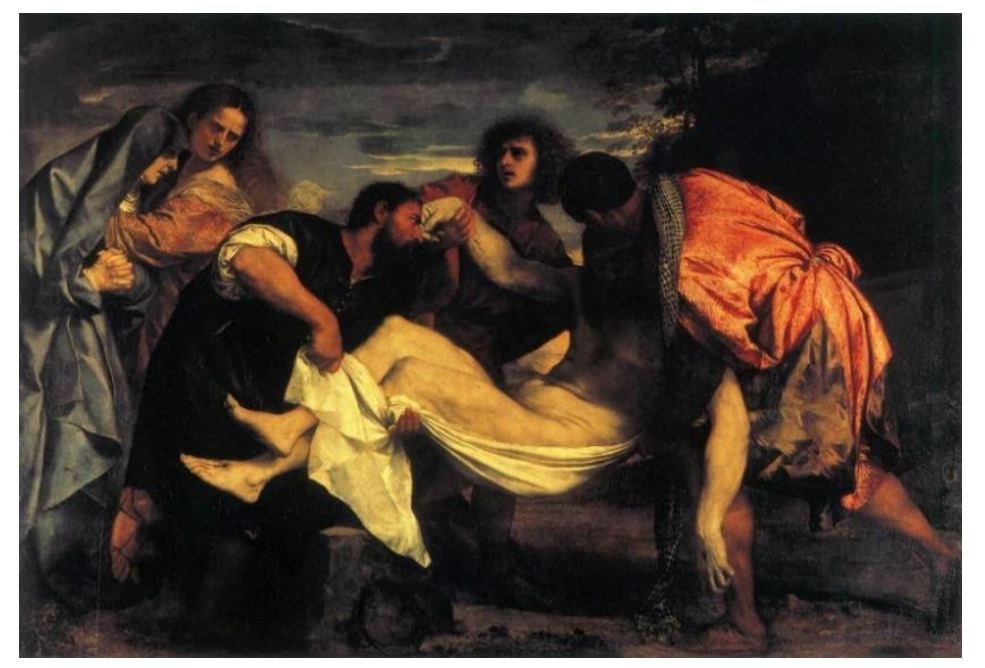

Figura 6. Tiziano Vecellio (Ticiano), 'O Sepultamento de Cristo' (c. 1520); óleo sobre tela; $148 x$ $212 \mathrm{~cm}$. Museu do Louvre, Coleção de Luís XIV, inv. 749. CC-PD-Mark. Digitalizado por The York Project (2002)

Ruskin se refere aqui ao Sepultamento de Cristo, de Ticiano, obra que ele admirou em suas visitas ao Louvre em 1844 e 1849. De fato, há apenas uma concha de caracol na pintura (no canto inferior direito), e Ruskin havia percebido isso em
1844. Provavelmente, sua intuição a respeito da importância desse detalhe multiplicou a presença da concha em sua memória.

Simbolicamente, o visual desta concha solitária na pintura de Ticiano expressa muito mais do que apenas a "umidade" do chão. A concha aparece de ponta cabeça e vazia. Ela serve de metáfora para a tumba da qual Cristo irá se levantar, e portanto nos convida a refletir sobre a promessa da ressurreição.

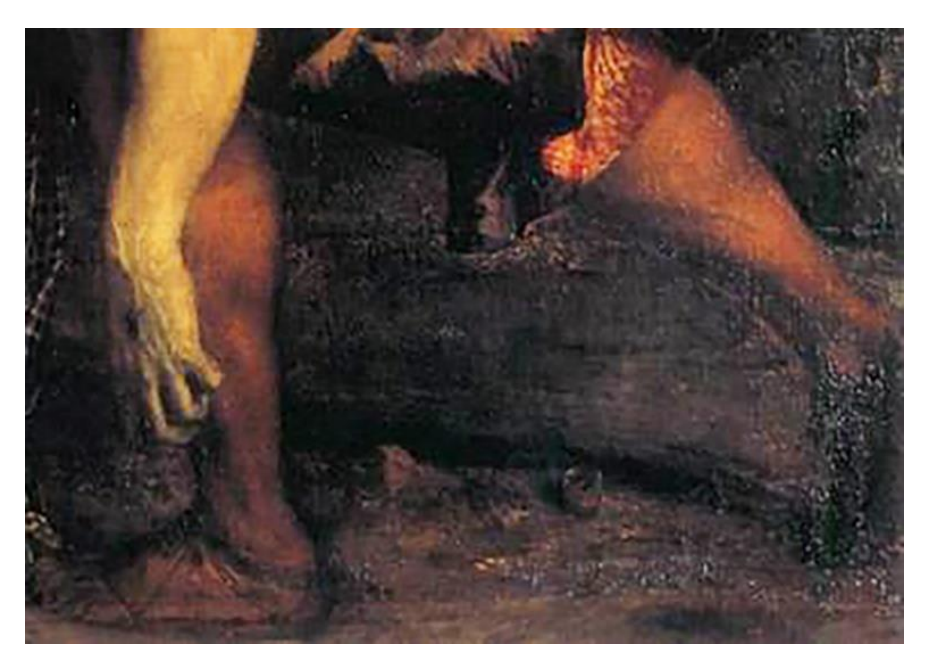

Figura 7. detalhe do 'Sepultamento de Cristo', de Ticiano (Fig. 6)

Ruskin também achava que aquela concha era símbolo da excelência de Ticiano como artista. -E Ruskin buscava emular essa excelência. Ele copiou aquela com-cha de caracol diversas vezes, e até incluiu um de seus desenhos em uma carta enviada a William Ward, em 15 de fevereiro de $1863 .{ }^{9}$

$\mathrm{Na}$ interpretação de Dance, esse desenho confirma que Ruskin via o 'design das conchas' como um marcador 'de genialidade', e eu concordo com essa ideia. Mas, para concluir, também gostaria de propor que conectemos esta apreciação artística do formato da concha com a moral implícita nas observações de Ruskin sobre os fósseis de conchas encontrados por ele em Boulogne.

${ }^{9}$ Veja Dance 2004, p.44. 
Se o fizermos, acredito que seremos capazes de ver como, para Ruskin, as conchas poderiam ser muito mais do que apenas um design. Elas poderiam ser exemplo de um tipo de cooperação que-assim como o pacto da ressurreiçãocarrega a promessa de vida duradoura.

\section{Referências}

BACHELARD, Gaston. La poétique de l'espace, $3^{\text {rd }}$ edn. Paris : Les Presses universitaires de France, 1961.

$\mathrm{BIRCH}$, Dinah. Ruskin and the science of Proserpina. In New approaches to Ruskin. Robert Hewison, ed. London: Routledge, 1981, p.142-56.

BROWNE, Daniel Jay. The field book of manures: or, the American muck book. New York: Saxton, Barker \& Co., 1852.

BURD, Van Akin. The Winnington letters. Cambridge, MASS: Harvard University Press, 1969

DANCE, S. Peter. Ruskin the reluctant conchologist'. Journal of the history of collections, Oxford Journals. n.16.1, p.35-46, 2004.

FREEMAN, Michael. Victorians and the prehistoric: tracks to a lost world. New Haven, CT: Yale University Press, 2004.

HEWISON, Robert. The Mind Revolts: Ruskin and Darwin. The Ruskin review, n.14.2, p.72-85, 2020.

MANHEIM, Ralph. Man and the Sea Shell. In Paul Valéry: an anthology. James R. Lawler, ed. Princeton: Princeton University Press, 1977, p.108-135. Collected Works of Paul Valéry, Bollingen Series n.45.

MANIFOLD, Janet. Time Unfolding: Ruskin to Rovelli (2019) <https://www.janetmanifold.co.uk/writing-category/5d26fb00509d1/Essays> [accessed 12.2.2019].

MEYNELL, Viola, ed. Friends of a lifetime: letters to Sydney Carlyle Cockerel. London: Jonathan Cape, 1940.
O'GORMANN, Francis. Ruskin's Science of the 1870s. In John Ruskin and the dawn of the modern. Dinah Birch, ed. Oxford: Oxford University Press, 1999, p. 35-55.

PLINY. Naturalis historiae: libri XXXVII. Vol. 3. Karl Mayhoff, eds. Stuttgart: B.G. Teubner, 1967.

RUSKIN, John. The Library edition of the works of John Ruskin. Vol. 8. London: George Allen, 1903.

RUSKIN, John. The Library edition of the works of John Ruskin. Vol. 15. London: George Allen, 1904.

RUSKIN, John. The Library edition of the works of John Ruskin. Vol. 17. London: George Allen, 1905a.

RUSKIN, John. The Library edition of the works of John Ruskin. Vol. 7. London: George Allen, $1905^{b}$.

RUSKIN, John. Fors Clavigera, Letter 63. In The Library edition of the works of John Ruskin. Vol. 28. London: George Allen, 1907. p.538-60.

SPEILMANN, W.H. John Ruskin: a sketch of his life, his work, and his opinions, with personal reminiscences. Philadelphia: J.B. Lippincott Company, 1900.

VALÉRY, Paul. L'Homme et la coquille, dessins par Henri Mondor. Paris: Gallimard, 1937.

VALLEMONT, Pierre le Lorrain de. Curiositez de la nature et de l'art sur la vegetation. Paris; Claude Cellier, 1705. 